\title{
Ação dos Herbicidas Atrazine e Glufosinate de Amônio no Aproveitamento de Nitrogênio pelas Plantas de Milho ${ }^{1}$
}

\author{
Herbicides Atrazine and Ammonium Glufosinate Action on Nitrogen Usage by \\ Corn Plants
}

FLECK, N.G. ${ }^{2}$, RIZZARDI, M.A. ${ }^{3}$, NEVES, R. ${ }^{4}$ e AGOSTINETTO, D. ${ }^{4}$

\begin{abstract}
RESUMO - A absorção vegetal do nitrogênio (N) presente no solo ou fornecido via fertilização é regulada por um complexo enzimático que age de forma conjunta e ordenada na planta. $\mathrm{O}$ objetivo desta pesquisa foi investigar efeitos dos herbicidas atrazine e glufosinate de amônio na absorção do $\mathrm{N}$ pelas plantas e os efeitos que exercem em características de plantas de milho. Em um dos experimentos (experimento 1) foram testadas três doses de atrazine $(0$, 200 e 2.000 g i.a. ha-1) e de glufosinate de amônio (0; 40 e 80 g i.a. ha $\left.{ }^{-1}\right)$ e duas doses de $\mathrm{N}(0$ e $90 \mathrm{~kg} \mathrm{ha}^{-1}$ ). No segundo experimento (experimento 2) foram testados três tratamentos herbicidas (atrazine, $200 \mathrm{~g}$ i.a. ha ${ }^{-1}$; glufosinate de amônio, $40 \mathrm{~g}$ i.a. ha ${ }^{-1}$; atrazine + glufosinate de amônio, $200+40$ g i.a. ha- ${ }^{-1}$; e testemunha), duas fontes de $\mathrm{N}$ (uréia e nitrato de amônio) e duas doses de $\mathrm{N}\left(0\right.$ e $\left.100 \mathrm{~kg} \mathrm{ha}^{-1}\right)$. Os efeitos dos tratamentos foram avaliados aos $10 \mathrm{e}$ 20 dias após a aplicação (DAA) dos herbicidas, no experimento 1, e quando as plantas de milho apresentavam 10 folhas desenvolvidas (15 DAA) e no pendoamento do milho (40 DAA), no experimento 2. A partir da análise dos resultados obtidos, constatou-se que aplicação de $\mathrm{N}$ em cobertura na cultura do milho promove aumento na maioria dos componentes do rendimento e incrementa em $35 \%$ o rendimento de grãos e que esse efeito ocorre de forma independente da fonte de $\mathrm{N}$ utilizada: uréia ou nitrato de amônio. Não ocorre interação entre os fatores relacionados aos herbicidas inibidores do fotossistema II (atrazine) e da sintese de glutamina (glufosinate de amônio) e aplicação de $\mathrm{N}$ em cobertura no milho. O uso destes herbicidas em doses reduzidas (abaixo da recomendada), aplicados isoladamente ou combinados, não afetou o rendimento de grãos nem os componentes do rendimento da cultura do milho. O herbicida atrazine tem pequena influência nos teores de clorofila e de $\mathrm{N}$ em milho, mas, em algumas situações, sua ação é favorável, especialmente quando usado na dose recomendada, ou mesmo isoladamente. Glufosinate de amônio, usado em doses reduzidas, em geral não afeta o teor de $\mathrm{N}$ em milho, porém, em alguns casos, afeta o de clorofila e, na dose de $80 \mathrm{~g} \mathrm{ha}^{-1}$, promove aumento do teor de $\mathrm{N}$ no tecido.
\end{abstract}

Palavras-chave: inibidor do fotossistema II, inibidor da síntese de glutamina, doses e fontes de nitrogênio.

\begin{abstract}
Plant absorption of nitrogen (N) present in soil or supplied through fertilization is regulated by a complex of enzymes that act in a jointly and ordered way in the plant. The purpose of this research was to investigate the effects of the herbicides atrazine and ammonium glufosinate in $N$ absorption by plants and their effects on corn plant traits. In one of the experiments (experiment $1)$, three atrazine rates were tested $\left(0,200\right.$, and $2000 \mathrm{~g}$ a.i. ha $\left.\mathrm{a}^{-1}\right)$, three ammonium glufosinate rates $\left(0,40\right.$, and $80 \mathrm{~g}$ a.i. ha $\left.{ }^{-1}\right)$, and two $N$ rates $\left(0\right.$ and $\left.90 \mathrm{~kg} \mathrm{ha}^{-1}\right)$. In another experiment (experiment 2), three herbicide treatments were tested (atrazine, $200 \mathrm{~g}$ a.i. ha $\mathrm{a}^{-1}$; ammonium glufosinate, $40 \mathrm{~g}$ a.i. ha $\mathrm{a}^{-1}$; atrazine + glufosinate, $200+40 \mathrm{~g}$ a.i. $\mathrm{ha}^{-1}$; and a check), two $\mathrm{N}$ sources (urea and ammonium nitrate), and two $N$ rates $\left(0\right.$ and $\left.100 \mathrm{~kg} \mathrm{ha}^{-1}\right)$. Effects of the treatments
\end{abstract}

Recebido para publicação em 29/8/2000 e na forma revisada em 26/1/2001.

2 Eng.-Agro., Ph.D., Professor do Departamento de Plantas de Lavoura da Faculdade de Agronomia da UFRGS, Bolsista do CNPq. Caixa Postal 776, 91501.970 Porto Alegre RS. ${ }^{3}$ Eng.-Agr ${ }^{\circ}$., Mestre, Professor da Faculdade de Agronomia e Medicina Veterinária da Universidade de Passo Fundo (UPF) e aluno do Programa de Pós-Graduação em Fitotecnia da UFRGS; ${ }^{4}$ Eng.-Agr ${ }^{\circ}$, aluno do Programa de Pós-Graduação em Fitotecnia da UFRGS.

Planta Daninha, Viçosa-MG, v.19, n.2, p.235-245, 2001 
were evaluated at 10 and 20 days after herbicide application (DAA) in experiment 1, and when corn plants presented 10 developed leaves (15 DAA) and at tasseling (4O DAA) in experiment 2. Statistical analyses revealed that $N$ side dressing application in corn promotes an increase in most of the grain yield components and increases grain yield by 35\%, and that such effects occur regardless of the $N$ source used, urea or ammonium nitrate. There was no interaction effect among factors related to herbicides that are inhibitors of photosystem II (atrazine) and to herbicides inhibitors of the glutamine synthesis (ammonium glufosinate) and $N$ side-dressing application in corn. The use of these herbicides in reduced rates, applied alone or in combination, did not affect grain yield nor yield components. Atrazine shows little consistency in affecting chlorophyll and N contents in corn; nevertheless, in some cases, its action is favorable, especially when used at the recommended rate or even when sprayed alone. Ammonium glufosinate, applied at reduced rates, in general does not affect $N$ content in corn; however, in some situations, chlorophyll content is affected and, when used at $80 \mathrm{~g}$ a.i. ha ${ }^{-1}$, promotes $N$ content increase in the corn tissue.

Key words: photosystem II inhibitor, glutamine synthesis inhibitor, nitrogen rates and sources.

\section{INTRODUÇÃO}

O nitrogênio (N) é um macronutriente fundamental no crescimento e desenvolvimento das plantas, por exercer importantes funções em processos bioquímicos e por constituir moléculas de proteínas, enzimas, coenzimas, ácidos nucléicos, fitocromos e clorofilas. Em muitos sistemas de produção, a disponibilidade de $\mathrm{N}$ é quase sempre um fator limitante, influenciando o crescimento das plantas mais do que qualquer outro nutriente (Bredemeier \& Mundstock, 2000). O N presente no solo ou fornecido via fertilização é absorvido como amônio $\left(\mathrm{NH}_{4}^{+}\right)$ou nitrato $\left(\mathrm{NO}_{3}^{-}\right)$(Lea, 1993). Subseqüentemente, o $\mathrm{N}$ é incorporado para formar ácido glutâmico por uma seqüência de reações catalisadas por enzimas como glutamina sintetase (GS) e glutamato sintase (GOGAT) e, no caso de a absorção ocorrer na forma nítrica, também pela nitrato redutase (NR) e nitrito redutase (NiR), enzimas que mediam a redução do $\mathrm{NO}_{3}{ }^{-}$(Lea, 1993). A maioria destas enzimas é dependente do suprimento de energia via $\mathrm{NAD}(\mathrm{P}) \mathrm{H}$ ou ferridoxina (Huppe \& Turpin, 1994).

Foi demonstrado por Devine et al. (1993) que determinados herbicidas influenciam algumas rotas metabólicas em culturas, direta ou indiretamente relacionadas ao metabolismo do N. No caso de herbicidas do grupo químico das triazinas, a atividade do fotossistema II (FSII) é inibida pelo fato de ocorrer a substituição da ligação da plastoquinona com a quinona $\mathrm{b}\left(\mathrm{Q}_{\mathrm{b}}\right)$. Estudos mostraram que atrazine substitui a forma oxidada da plastoquinona e ocupa o local de ligação específico no aceptor $\mathrm{Q}_{\mathrm{b}}$ na proteína $\mathrm{D}_{1}$ (Kleczkowski, 1993). Desse modo, como a molécula do herbicida está reduzida, não estando apta a receber elétrons, sua ligação bloqueia efetivamente o fluxo de elétrons, inibindo a fotossíntese.

Existem relatos de trabalhos que indicam aumento no crescimento e no conteúdo de $\mathrm{N}$ em plantas tratadas com subdoses de atrazine (Mohanadas et al., 1978; Klepper, 1979). Entretanto, apesar destes relatos, ainda há opiniões divergentes sobre o acúmulo de $\mathrm{N}$ nas plantas causado pelas triazinas (Ashton \& Crafts, 1973). O efeito dos herbicidas inibidores do FSII pode estar associado à ação tanto sobre NR quanto sobre NiR. A enzima cloroplástica (NiR) é dependente do fluxo de elétrons da ferridoxina, a qual é usada pela enzima como redutor. Inibidores do transporte de elétrons fotossintéticos paralisam a redução do $\mathrm{NO}_{3}{ }^{-}$a $\mathrm{NH}_{4}{ }^{+}$. Caso $\mathrm{O} \mathrm{NO}_{3}{ }^{-}$continue a ser reduzido no citoplasma, ocorre acúmulo de níveis tóxicos de $\mathrm{NO}_{2}{ }^{-}$, ácido nitroso e radicais livres $\mathrm{No}_{x}$ (Churchill \& Klepper, 1979; Devine et al., 1993). Assim, em plantas adubadas com $\mathrm{NO}_{3}{ }^{-}$, herbicidas inibidores fotossintéticos podem causar rápido acúmulo de altas concentrações de $\mathrm{NO}_{2}$. No entanto, não é relatado efeito significativo direto de nenhum herbicida sobre a enzima NR, mas herbicidas inibidores do FSII podem aumentar a quantidade de NR em tecidos verdes (Devine et al., 1993). Aumentos 
no rendimento de proteínas, associados com incremento na NR em culturas tratadas com doses subletais de atrazine, foram relacionados à possível ação deste herbicida como regulador de crescimento (Devine et al., 1993).

Na maioria dos solos, $\mathrm{NH}_{4}^{+}$e $\mathrm{NO}_{3}^{-}$são as fontes de $\mathrm{N}$ disponíveis para a nutrição das plantas, com a primeira fonte necessitando de menos energia para a absorção de $\mathrm{N}$ do que a segunda (Von Wirén et al., 2000). Esta menor necessidade de energia da forma $\mathrm{NH}_{4}^{+}$pode interferir no efeito das triazinas no metabolismo do N. Nesse contexto, Mohanadas et al. (1978) salientam que o efeito diferencial de atrazine no crescimento das plantas de milho supridas com $\mathrm{NO}_{3}^{-}$, em comparação com $\mathrm{NH}_{4}^{+}$, pode ser explicado em termos de absorção e incorporação destes compostos nas plantas. $\mathrm{NO}_{3}^{-} \mathrm{e}$ outros ânions são absorvidos de forma ativa, mas cátions como $\mathrm{NH}_{4}^{+}$são absorvidos de forma passiva. Além disso, o aumento na absorção de $\mathrm{NO}_{3}$ - provocado por atrazine deve-se aos seus efeitos no sistema de carregadores de $\mathrm{NO}_{3}^{-}$, sendo estes dependentes de energia (Von Wirên et al., 2000).

A assimilação do N, juntamente com a de $\mathrm{CO}_{2}$, constitui-se na principal função de uma célula foliar. Há evidências de que a principal rota de assimilação do $\mathrm{NH}_{4}^{+}$produzido nos tecidos foliares é sua conversão em glutamina, seguida pela formação de glutamato, em reações mediadas pelas enzimas GS e GOGAT (Lam et al., 1995). A biossíntese e o metabolismo destes e de outros aminoácidos (glicina, serina, alanina, aspartato e asparagina) em plantas estão estreitamente associados com processos fotossintéticos (Huppe \& Turpin, 1994). A assimilação de $\mathrm{N}$ em folhas está associada a reações acopladas da GS e GOGAT dependentes de ferridoxina, resultando na incorporação de $\mathrm{NH}_{4}{ }^{+}$em glutamato. A GS é o local primário da assimilação de N, catalisando a reação de $\mathrm{NH}_{4}^{+}$a glutamato e originando glutamina, sendo tal reação potencialmente inibida pelo herbicida glufosinate (Hess, 1995).

A inibição de GS causa rápido acúmulo nos niveis de $\mathrm{NH}_{4}{ }^{+}$intracelular, associada à ruptura da estrutura do cloroplasto, resultando na inibição da fotossíntese e na morte das células da planta. Embora a toxicidade de $\mathrm{NH}_{4}{ }^{+}$pareça ser o mecanismo de ação primário do glufosinate, $\mathrm{NH}_{4}^{+}$pode não ser a causa principal da morte da célula na presença do inibidor. Além da toxicidade de $\mathrm{NH}_{4}^{+}$, o efeito do herbicida na fotossintese pode ser explicado pela inibição da síntese de proteínas (especialmente proteína $\mathrm{Q}_{\mathrm{b}}$ envolvida no transporte de elétrons), pelo acúmulo de glioxalato tóxico devido à deficiência de aminoácidos doadores ou pela insuficiente regeneração de intermediários do ciclo $\mathrm{C}_{3}$ (Devine et al., 1993; Kleczkowski, 1993).

Assim, pelo fato de atrazine influenciar o metabolismo do $\mathrm{N}$ pela ação que exerce sobre as enzimas NR e NiR, ou mesmo pelo aumento no conteúdo de glutamina (Mohanadas et al., 1978), e de o glufosinate influenciar o metabolismo do N, por atuar sobre a GS, é possível que haja interação destes herbicidas quando em mistura. Ou seja, a diminuição no conteúdo de glutamina pela ação do glufosinate na GS poderia ser compensada pelo efeito de atrazine na disponibilidade de $\mathrm{N}$ e, também, de glutamina. O objetivo deste trabalho foi investigar efeitos dos herbicidas atrazine e glufosinate na absorção do $\mathrm{N}$ pelas plantas e os efeitos que exercem em características de plantas de milho.

\section{MATERIAL E MÉTODOS}

Dois experimentos foram conduzidos em campo durante as estações de crescimento de 1997/98 e 1999/00, na Estação Experimental Agronômica da Universidade Federal do Rio Grande do Sul (EEA/UFRGS), localizada no município de Eldorado do Sul, região fisiográfica da Depressão Central do Rio Grande do Sul. O solo da área experimental é classificado como Argissolo Vermelho Distrófico típico (Embrapa, 1999). Antecedendo à instalação de cada experimento, as áreas foram amostradas para análise do solo, tendo sido obtidos os seguintes resultados: experimento 1: $38 \mathrm{~g}$ de argila por kg de solo, $\mathrm{pH}$ (em água) de 5,2, $9 \mathrm{mg}$ de $\mathrm{P}_{2} \mathrm{O}_{5}$ por $\mathrm{dm}^{3}, 168 \mathrm{mg}$ de $\mathrm{K}_{2} \mathrm{O}$ por $\mathrm{dm}^{3}$ e $3,4 \mathrm{~g}$ de matéria orgânica por kg de solo; e experimento 2: $28 \mathrm{~g}$ de argila por $\mathrm{kg}$ de solo, $\mathrm{pH}$ (em água) de 5,2, $16 \mathrm{mg}$ de $\mathrm{P}_{2} \mathrm{O}_{5}$ por $\mathrm{dm}^{3}, 134 \mathrm{mg}$ de $\mathrm{K}_{2} \mathrm{O}$ por $\mathrm{dm}^{3}$ e 2,6 g de matéria orgânica por $\mathrm{kg}$ de solo.

O delineamento experimental empregado nos dois experimentos foi o de blocos 
completamente casualizados, dispostos em esquema fatorial. Foram utilizadas quatro e cinco repetições no primeiro e segundo experimentos, respectivamente.

No experimento 1 (1997/98), os fatores constaram de três doses dos herbicidas atrazine e glufosinate e de duas doses de nitrogênio. As doses do herbicida atrazine utilizadas foram de 0,200 e $2.000 \mathrm{~g} \mathrm{ha}^{-1}$; as subdoses do herbicida glufosinate foram de 0,40 e $80 \mathrm{~g} \mathrm{ha}^{-1}$. Como terceiro fator, foram usados tratamentos de 0 e $90 \mathrm{~kg}$ de $\mathrm{N} \mathrm{ha}^{-1}$ (200 kg de uréia ha-1). Cada unidade experimental mediu $12 \mathrm{~m}^{2}$, constando de quatro fileiras de plantas de milho.

No experimento 2 (1999/00), os três fatores estudados constaram de quatro tratamentos herbicidas, de duas fontes e de duas doses de nitrogênio. Os tratamentos herbicidas testados foram: glufosinate (40 $\left.\mathrm{g} \mathrm{ha}^{-1}\right)$, atrazine (200 $\mathrm{g} \mathrm{ha}^{-1}$ ), glufosinate + atrazine em aplicação seqüencial ( 40 e $200 \mathrm{~g} \mathrm{ha}^{-1}$ ) e testemunha. Como segundo fator, usaram-se duas fontes de nitrogênio-uréia e nitrato de amônio. As doses de nitrogênio, constituindo o terceiro fator, foram de 0 e $100 \mathrm{~kg}$ de $\mathrm{N} \mathrm{ha}^{-1}(222 \mathrm{~kg}$ de uréia ha ${ }^{-1}$ ou $333 \mathrm{~kg}$ de nitrato ha-1). Cada unidade experimental mediu $24,5 \mathrm{~m}^{2}$, sendo formada por cinco fileiras de plantas de milho.

Em ambos os experimentos a semeadura do milho foi realizada no sistema de semeadura direta, sendo a cobertura constituída por palha de aveia preta em 1997/98 e pela associação de aveia preta com ervilhaca em 1999/00.

Em 1997/98, utilizou-se como genótipo reagente o híbrido de milho XL-212, semeado à densidade de 70 mil plantas ha-1, em espaçamento de 0,7 $\mathrm{m}$ entre fileiras. A semeadura foi realizada em 17 de setembro de 1997 e a colheita das espigas ocorreu no dia 9 de fevereiro de 1998. A adubação de base foi feita com $45 \mathrm{~kg}$ de $\mathrm{N} \mathrm{ha}^{-1}, 120 \mathrm{~kg}$ de $\mathrm{P}_{2} \mathrm{O}_{5}$ ha $^{-1}$ e $100 \mathrm{~kg}$ de $\mathrm{K}_{2} \mathrm{O}$ ha $^{-1}$, juntamente com a operação de semeadura. A adubação nitrogenada de cobertura foi realizada de acordo com os tratamentos propostos, quando as plantas de milho apresentavam quatro a cinco folhas (quatro dias antes da aplicação dos tratamentos herbicidas). Os herbicidas foram aplicados em pós-emergência, quando as plantas de milho apresentavam-se com quatro a seis folhas desenvolvidas. Para as aspersões dos produtos usou-se um pulverizador costal de precisão, operado à pressão constante de $200 \mathrm{kPa}$, empregando-se bicos de jato plano, em leque, série 110.03 , os quais propiciaram volume de calda equivalente a $250 \mathrm{~L} \mathrm{ha}^{-1}$. As plantas daninhas foram controladas com aplicação de nicosulfuron (60 $\left.\mathrm{g} \mathrm{ha}^{-1}\right)$ em pós-emergência, cinco dias após as aplicações dos tratamentos herbicidas.

Em 1999/00, utilizou-se o híbrido de milho 30R07 à densidade de 68 mil plantas ha ${ }^{-1}$, em espaçamento de 0,7 m entre fileiras. As sementes de milho foram previamente tratadas com thiodicarb ( $1 \mathrm{~L}$ de produto comercial $/ 50 \mathrm{~kg}$ de sementes). A semeadura da cultura foi realizada em 18 de outubro de 1999. A adubação de base foi feita com $35 \mathrm{~kg}$ de $\mathrm{N} \mathrm{ha}^{-1}, 140 \mathrm{~kg}$ de $\mathrm{P}_{2} \mathrm{O}_{5}$ ha $^{-1}$ e $140 \mathrm{~kg} \mathrm{de}_{2} \mathrm{O} \mathrm{ha}^{-1}$. As plantas daninhas foram controladas com aplicação do herbicida nicosulfuron (60 $\left.\mathrm{g} \mathrm{ha}^{-1}\right)$ em pós-emergência, quando as plantas de milho apresentavam quatro folhas desenvolvidas. A adubação nitrogenada de cobertura foi realizada de acordo com os tratamentos propostos, quando as plantas de milho apresentavam seis folhas desenvolvidas (quatro dias antes da aplicação dos tratamentos herbicidas). Os herbicidas glufosinate $\left(40 \mathrm{~g} \mathrm{ha}^{-1}\right)+\operatorname{Agral}(0,1 \% \mathrm{v} / \mathrm{v}) \mathrm{e}$ atrazine (200 $\left.\mathrm{g} \mathrm{ha}^{-1}\right)+$ óleo mineral foram aplicados quando as plantas de milho apresentavam-se com seis a sete folhas desenvolvidas. Logo após a aplicação dos tratamentos de atrazine ocorreu uma chuva leve, a qual pode ter removido parte da aplicação do herbicida retido pelas folhas de milho. Em razão disso, efetuou-se uma segunda aplicação de atrazine uma hora após a primeira, na qual se utilizou a metade da dose prevista, supondo-se que metade da primeira aplicação tivesse sido removida pela chuva. Para realizar as aspersões, utilizou-se pulverizador costal de precisão, operado à pressão constante de $200 \mathrm{kPa}$, com volume de calda equivalente a $200 \mathrm{~L} \mathrm{ha}^{-1}$. A colheita foi realizada em 20 de fevereiro de 2000 , por meio da coleta das espigas nas duas linhas centrais de cada parcela.

Os insetos-praga foram controlados de modo que seu dano não prejudicasse o desenvolvimento da cultura. Os experimentos foram conduzidos sob condição de suplementação hídrica, por meio de irrigações periódicas efetuadas por aspersão. 
Os efeitos dos tratamentos foram estimados a partir de avaliações realizadas aos $10 \mathrm{e}$ 20 dias após a aplicação (DAA) dos herbicidas, no experimento 1, e quando as plantas de milho apresentavam 10 folhas desenvolvidas (15 DAA) e no pendoamento do milho (40 DAA), no experimento 2. Em ambos os experimentos, as avaliações de campo constaram da obtenção de massa seca da parte aérea (determinada em cinco plantas por parcela), rendimento de grãos e componentes do rendimento; no segundo experimento, foi realizada avaliação do teor de clorofila (em cinco plantas por parcela), o qual foi determinado em dois pontos da última folha completamente desenvolvida (base e ápice da folha), com auxílio de um medidor portátil de clorofila (que propicia leituras instantâneas, SPAD - Soil Plant Analysis Development). Na primeira avaliação, a leitura do teor de clorofila foi feita na nona folha e, na segunda, na folha indice. Em laboratório, foi avaliado o teor de nitrogênio a partir das plantas coletadas, para determinação da massa seca. O teor de nitrogênio total no tecido foi determinado de acordo com metodologia descrita por Tedesco et al. (1985). A quantidade de nitrogênio absorvida foi obtida multiplicando-se a produção de massa seca da parte aérea da planta pelo teor de $\mathrm{N}$ presente na respectiva fitomassa. Para cada uma das épocas de avaliação do teor de N, também foi calculada a eficiência de utilização do $\mathrm{N}$ (EUN), com base na razão entre o rendimento (grãos ou massa seca) e o $\mathrm{N}$ acumulado na planta.

Os dados coletados nos experimentos foram submetidos à análise de variância pelo teste de F; quando indicada significância estatística para a variável, as médias dos tratamentos foram comparadas por meio do teste de Duncan, utilizando-se o nível de significância de 5\% de probabilidade.

\section{RESULTADOS E DISCUSSÃO}

No experimento 1 , verificou-se que a utilização de $\mathrm{N}$ em cobertura (90 kg ha-1) incrementou a maioria das variáveis avaliadas, exceto o peso de 1.000 grãos e o teor de $\mathrm{N}$ nos grãos de milho (Tabelas 1 e 2). A variável menos afetada pela adubação foi o número de espigas por planta $(8,5 \%$ de acréscimo), enquanto o teor de $\mathrm{N}$ na massa seca das plantas, aos 20 DAA, foi a variável mais afetada (75\% de aumento). O incremento no rendimento de grãos ocasionado pelo uso de $\mathrm{N}$ em cobertura foi de $35 \%$. No experimento 2 , a aplicação de $\mathrm{N}$ em cobertura incrementou significativamente os valores obtidos em todas as variáveis determinadas, exceto a massa seca e o número de espigas por planta (Tabelas 3 a 5). Os incrementos obtidos variaram desde $6 \%$ para peso de 1.000 grãos até $47 \%$ para teor de $\mathrm{N}$ na massa seca da planta de milho no estádio do pendoamento. Para rendimento de grãos, a utilização de $100 \mathrm{~kg} \mathrm{ha}^{-1}$ de $\mathrm{N}$ ocasionou acréscimo de $35 \%$ na variável.

Nos dois anos de condução da pesquisa, observaram-se efeitos dos herbicidas testados no conteúdo de $\mathrm{N}$ na massa seca da planta de milho. Em 1997/98, nas avaliações de $\mathrm{N}$ na fitomassa, a análise estatística constatou somente efeitos simples dos tratamentos herbicidas (Tabela 1). Na avaliação da porcentagem de $\mathrm{N}$ na fitomassa, realizada aos 10 DAA, não foi observado efeito do herbicida glufosinate (Tabela 1). A aplicação da dose cheia de atrazine (2.000 $\mathrm{g} \mathrm{ha}^{-1}$ ) aumentou em 11\% o teor de $\mathrm{N}$ na fitomassa em relação à testemunha e em $15 \%$ em relação à subdose deste produto, embora estes valores não sejam significativos. De forma semelhante, aos 20 DAA, o uso de atrazine influenciou o teor de $\mathrm{N}$, sendo o menor percentual de variação relativa observado na subdose de $200 \mathrm{~g} \mathrm{ha}^{-1}$ (Tabela 1). Nesta avaliação, em valores relativos, a utilização da dose mais alta de glufosinate aumentou em 13\% o teor de $\mathrm{N}$ em relação à testemunha sem aplicação do herbicida. Em 1999/2000, também foi constatado apenas efeito simples dos tratamentos herbicidas (Tabela 3). Neste ano, verificou-se efeito dos herbicidas no teor de $\mathrm{N}$ somente na segunda avaliação, realizada no florescimento do milho, em que a utilização de subdose de glufosinate reduziu o $\mathrm{N}$ tanto na aplicação isolada (8\%) como quando aplicado seqüencialmente a atrazine (10\%) (Tabela 3).

Há considerável número de referências na literatura sobre o efeito de diversos herbicidas no metabolismo do N (Klepper, 1975 e 1976; Fedtke, 1977; Mohanadas et al., 1978; Singh et al., 1998). Nestes trabalhos, os resultados são bastante variáveis, dependendo do experimento, do herbicida, da espécie vegetal, do 
estádio de desenvolvimento, do tecido tratado e das condições de crescimento das plantas (Duke, 1985). Ao se analisar de forma conjunta os dois experimentos, percebem-se variações nos efeitos dos herbicidas sobre o teor de $\mathrm{N}$ (Tabelas 1 e 3). No caso do herbicida atrazine, sua ação no metabolismo está associada ao fornecimento de energia às enzimas NR e NiR (Mohanadas et al., 1978; Klepper, 1979), responsáveis pela redução do nitrato. No primeiro ano, foi utilizado $\mathrm{N}$ na forma amoniacal; entretanto, como o conteúdo deste macronutriente no solo era alto, é possível que houvesse alta disponibilidade de $\mathrm{N}$ na forma nítrica, o que explicaria o efeito positivo do uso de atrazine. No segundo ano, constatou-se que, para nenhuma das variáveis avaliadas, houve diferenças entre as fontes de $\mathrm{N}$ utilizadas (Tabelas 3 a 5). Nessa condição, é possível que o fornecimento de $\mathrm{N}$ na forma amoniacal ou nítrica tenha sido mascarado pela alta disponibilidade destas formas de $\mathrm{N}$ no solo, ou mesmo pela adubação nitrogenada realizada quando da semeadura do milho. Nesse contexto, Ashton \& Crafts (1973) salientam que niveis maiores de $\mathrm{N}$ nas plantas, como resultado de quantidades subtóxicas de simazine, são mais prováveis de ser demonstrados em baixos níveis de $\mathrm{N}$ disponíveis e sob condições adversas de ambiente.

Os efeitos positivos do uso da dose de $80 \mathrm{~g} \mathrm{ha}^{-1}$ de glufosinate no teor de $\mathrm{N}$ da fitomassa, observados no primeiro ano, podem estar associados a um efeito indireto desta dose no metabolismo do N. A ação principal deste herbicida dá-se na inibição da GS, o que acarretaria acúmulo de $\mathrm{NH}_{4}^{+}$, influenciando negativamente o metabolismo do $\mathrm{N}$, como foi observado no segundo ano (Tabela 3). A hipótese inicial de que haveria interação de atrazine e glufosinate, quando em mistura, não foi confirmada para teor de $\mathrm{N}$ na fitomassa. Embora possa ter havido efeito herbicida sobre as enzimas NR e GS, ou mesmo sobre o conteúdo de glutamina (Mohanadas et al., 1978), estudos têm mostrado que o metabolismo do N é multirregulado e integrado ao metabolismo geral da planta (Bredemeier \& Mundstock, 2000). Assim, o acúmulo de $\mathrm{NH}_{4}^{+}$, propiciado pelo uso de glufosinate, pode ter ocasionado inibição no mecanismo de absorção de $\mathrm{N}$, inibindo a NR pelo acúmulo do produto final, no caso $\mathrm{NH}_{4}{ }^{+}$. Este mecanismo de regulação enzimática é salientado por Devine et al. (1993); segundo estes autores, o glufosinate inibe a NR pela inibição na absorção de $\mathrm{NO}_{3}{ }^{-}$. Assim, a atividade da NR pode ser diretamente diminuída pelos niveis altos de $\mathrm{NH}_{4}^{+}$; entretanto, em alfafa tratada com glufosinate, a redução na atividade da NR ocorreu antes de aumentarem os níveis de $\mathrm{NH}_{4}^{+}$(Devine et al., 1993). Outra explicação está associada ao fato de a absorção tanto de $\mathrm{NO}_{3}{ }^{+}$quanto de outros ânions ser inibida por efeito direto na despolarização da plasmalema e, devido ao acúmulo de $\mathrm{NH}_{3}{ }^{+}$, ocorrer a alcalinização do citosol e o desacoplamento do transporte de elétrons (Von Wirén et al., 2000).

Os efeitos dos tratamentos herbicidas na massa seca somente foram observados no experimento realizado em 1997/98, no qual se constatou que a maior dose de atrazine reduziu a massa seca da parte aérea das plantas de milho em ambas as avaliações realizadas (Tabela 1). No segundo ano, os valores de massa seca para a primeira e segunda avaliações não foram influenciados pelos fatores e tratamentos testados (Tabela 4). Os tratamentos com atrazine e de glufosinate não influenciaram a quantidade de N na massa seca em 1997/98, (Tabela 1). Em 1999/00, o efeito dos tratamentos herbicidas na quantidade de nitrogênio na massa seca diferiu do observado para porcentagem de N (Tabela 3). Neste ano, a utilização de atrazine aumentou a quantidade de $\mathrm{N}$ na fitomassa na primeira época. Nessa época de avaliação, o aumento foi de 13\% quando atrazine foi aplicado isoladamente. Nos dois anos de condução do trabalho, o uso de subdoses do herbicida glufosinate aplicado isoladamente não influenciou a quantidade de $\mathrm{N}$ na massa seca (Tabelas 1 e 3).

Os efeitos dos herbicidas no metabolismo do $\mathrm{N}$ descritos na literatura são conflitantes e, em muitos casos, difíceis de explicar. Para Ashton \& Crafts (1973), em muitos trabalhos, os efeitos de herbicidas como atrazine estão mais associados à redução no crescimento da planta do que ao aumento na absorção de N, ou seja, o aumento na porcentagem das frações de $\mathrm{N}$ tem sido atribuído a uma diminuição no peso da massa seca, em vez de aumento real no N. 
Tabela 1 - Efeitos de aplicações dos herbicidas atrazine e glufosinate e de adubo nitrogenado em características de plantas de milho. EEA/UFRGS, Eldorado do Sul-RS, 1997/98

\begin{tabular}{|c|c|c|c|c|c|c|}
\hline \multirow{3}{*}{$\begin{array}{c}\text { Fatores e } \\
\text { tratamentos }\end{array}$} & \multirow{2}{*}{\multicolumn{2}{|c|}{$\begin{array}{c}\text { Massa seca da parte } \\
\text { aérea } \\
\text { Quantidade por planta } \\
(\mathrm{g})\end{array}$}} & \multicolumn{4}{|c|}{ Nitrogênio na massa seca } \\
\hline & & & \multicolumn{2}{|c|}{ Porcentagem } & \multicolumn{2}{|c|}{ Quantidade (mg planta $\left.{ }^{-1}\right)$} \\
\hline & $10 \mathrm{DAA}^{\underline{1}}$ & $20 \mathrm{DAA}$ & $10 \mathrm{DAA}$ & $20 \mathrm{DAA}$ & $10 \mathrm{DAA}$ & $20 \mathrm{DAA}$ \\
\hline \multicolumn{7}{|c|}{ Doses de N $\left(\mathrm{kg} \mathrm{ha}^{-1}\right)$} \\
\hline 0 & $9,24 \mathrm{~b}$ & $23,3 \mathrm{~b}$ & $2,26 \mathrm{~b}$ & $2,14 \mathrm{~b}$ & $202 \mathrm{~b}$ & $498 \mathrm{~b}$ \\
\hline 90 & $11,27 \mathrm{a}$ & $32,5 \mathrm{a}$ & $3,12 \mathrm{a}$ & $2,68 \mathrm{a}$ & $347 \mathrm{a}$ & $873 \mathrm{a}$ \\
\hline \multicolumn{7}{|l|}{ Atrazine $\left(\mathrm{g} \mathrm{ha}^{-1}\right)$} \\
\hline 0 & $10,99 \mathrm{a}^{2}$ & $28,3 \mathrm{ab}$ & $2,62 \mathrm{~b}$ & $2,44 \mathrm{ab}$ & 293 a & $705 \mathrm{a}$ \\
\hline 200 & $10,77 \mathrm{ab}$ & $30,5 \mathrm{a}$ & $2,52 \mathrm{~b}$ & $2,28 \mathrm{~b}$ & $277 \mathrm{a}$ & $706 \mathrm{a}$ \\
\hline 2.000 & $8,99 \mathrm{~b}$ & $24,8 \mathrm{~b}$ & $2,90 \mathrm{a}$ & $2,51 \mathrm{a}$ & $248 \mathrm{a}$ & $629 a$ \\
\hline \multicolumn{7}{|c|}{ Glufosinate $\left(\mathrm{g} \mathrm{ha}^{-1}\right)$} \\
\hline 0 & $10,92 \mathrm{a}$ & $28,8 \mathrm{a}$ & $2,63 \mathrm{a}$ & $2,29 \mathrm{~b}$ & $279 \mathrm{a}$ & $669 \mathrm{a}$ \\
\hline 40 & $10,36 \mathrm{a}$ & $28,1 \mathrm{a}$ & $2,67 \mathrm{a}$ & $2,34 \mathrm{~b}$ & $280 \mathrm{a}$ & $669 a$ \\
\hline 80 & $9,48 \mathrm{a}$ & $26,7 \mathrm{a}$ & $2,75 \mathrm{a}$ & $2,60 \mathrm{a}$ & $259 \mathrm{a}$ & $702 \mathrm{a}$ \\
\hline Médias & 10,24 & 27,8 & 2,68 & 2,41 & 273 & 680 \\
\hline $\mathrm{CV}(\%)$ & 31,14 & 26,30 & 16,89 & 12,87 & 33,87 & 30,29 \\
\hline
\end{tabular}

1/ Dias após aplicação dos herbicidas.

2` Médias de tratamentos comparadas nas colunas, dentro do mesmo fator, seguidas por letras idênticas, não diferem significativamente pelo teste de Duncan, a 5\% de probabilidade.

Tabela 2 - Efeitos de aplicações dos herbicidas atrazine e glufosinate e de adubo nitrogenado em características de plantas de milho. EEA/UFRGS, Eldorado do Sul-RS, 1997/98

\begin{tabular}{|c|c|c|c|c|}
\hline \multirow{2}{*}{$\begin{array}{c}\text { Fatores e } \\
\text { tratamentos }\end{array}$} & \multicolumn{4}{|c|}{ Características de plantas e grãos de milho } \\
\hline & $\begin{array}{l}\text { Espigas por planta } \\
\qquad\left(\mathrm{n}^{\circ}\right)\end{array}$ & $\begin{array}{c}\text { Grãos por espiga } \\
\left(n^{\underline{o}}\right)\end{array}$ & $\begin{array}{c}\text { Peso de } 1.000 \text { grãos } \\
(\mathrm{g})\end{array}$ & $\begin{array}{l}\text { Rendimento de } \\
\text { grãos }\left(\mathrm{kg} \mathrm{ha}^{-1}\right)\end{array}$ \\
\hline \multicolumn{5}{|c|}{ Doses de N (kg ha $\left.{ }^{-1}\right)$} \\
\hline 0 & $0,94 \mathrm{~b}$ & $336 \mathrm{a}$ & $239 \mathrm{a}$ & $4.762 \mathrm{~b}$ \\
\hline 90 & $1,02 \mathrm{a}$ & $391 \mathrm{a}$ & $246 \mathrm{a}$ & $6.422 \mathrm{a}$ \\
\hline \multicolumn{5}{|l|}{ Atrazine $\left(\mathrm{g} \mathrm{ha}^{-1}\right)$} \\
\hline 0 & $0,98 \mathrm{a}^{1 /}$ & $364 \mathrm{a}$ & $238 \mathrm{~b}$ & $5.505 \mathrm{a}$ \\
\hline 200 & $0,96 \mathrm{a}$ & $346 \mathrm{a}$ & $235 \mathrm{~b}$ & $5.275 \mathrm{a}$ \\
\hline 2.000 & $1,01 \mathrm{a}$ & $378 \mathrm{a}$ & $254 \mathrm{a}$ & $5.960 \mathrm{a}$ \\
\hline \multicolumn{5}{|c|}{ Glufosinate $\left(\mathrm{g} \mathrm{ha}^{-1}\right)$} \\
\hline 0 & $0,98 \mathrm{a}$ & $382 \mathrm{a}$ & $244 \mathrm{a}$ & $5.780 \mathrm{a}$ \\
\hline 40 & $0,97 \mathrm{a}$ & $360 \mathrm{a}$ & $234 \mathrm{a}$ & $5.488 \mathrm{a}$ \\
\hline 80 & $0,99 \mathrm{a}$ & $348 \mathrm{a}$ & $249 \mathrm{a}$ & $5.500 \mathrm{a}$ \\
\hline Médias & 0,98 & 363 & 243 & 5.592 \\
\hline $\mathrm{CV}(\%)$ & 14,86 & 20,24 & 10,00 & 27,83 \\
\hline
\end{tabular}

${ }^{1}$ Médias de tratamentos comparadas nas colunas, dentro do mesmo fator, seguidas por letras idênticas, não diferem significativamente pelo teste de Duncan, a 5\% de probabilidade. 
Tabela 3 - Efeitos de aplicações de herbicidas e de fontes e doses de nitrogênio em características de plantas de milho. EEA/ UFRGS, Eldorado do Sul-RS, 1999/00

\begin{tabular}{|c|c|c|c|c|}
\hline \multirow{2}{*}{ Fatores e tratamentos } & \multicolumn{2}{|c|}{ Nitrogênio na massa seca (\%) } & \multicolumn{2}{|c|}{ Nitrogênio na massa seca (g) } \\
\hline & Época $1^{\underline{1} /}$ & Época $2^{\frac{1}{}}$ & Época 1 & Época 2 \\
\hline \multicolumn{5}{|l|}{ Fontes de nitrogênio } \\
\hline Uréia & $2,39 \mathrm{a}^{2 !}$ & $1,39 \mathrm{a}$ & $1,17 \mathrm{a}$ & $2,11 \mathrm{a}$ \\
\hline Nitrato de amônio & $2,47 \mathrm{a}$ & $1,42 \mathrm{a}$ & $1,20 \mathrm{a}$ & $2,10 \mathrm{a}$ \\
\hline \multicolumn{5}{|l|}{ Doses de N (kg ha $\left.{ }^{-1}\right)$} \\
\hline 0 & $2,07 \mathrm{~b}$ & $1,14 \mathrm{~b}$ & $1,01 \mathrm{~b}$ & $1,70 \mathrm{~b}$ \\
\hline 100 & $2,78 \mathrm{a}$ & $1,67 \mathrm{a}$ & $1,35 \mathrm{a}$ & $2,51 \mathrm{a}$ \\
\hline \multicolumn{5}{|l|}{ Herbicidas } \\
\hline Testemunha & $2,37 \mathrm{a}$ & $1,49 \mathrm{a}$ & $1,12 \mathrm{~b}$ & $2,19 \mathrm{a}$ \\
\hline Glufosinate & $2,42 \mathrm{a}$ & $1,37 \mathrm{~b}$ & $1,14 \mathrm{~b}$ & $2,09 \mathrm{a}$ \\
\hline Atrazine & $2,50 \mathrm{a}$ & $1,43 a b$ & $1,27 \mathrm{a}$ & $2,15 \mathrm{a}$ \\
\hline Glufosinate + atrazine & $2,41 \mathrm{a}$ & $1,34 \mathrm{~b}$ & $1,20 \mathrm{ab}$ & $1,98 \mathrm{a}$ \\
\hline Médias & 2,43 & 1,40 & 1,18 & 2,10 \\
\hline $\mathrm{CV}(\%)$ & 10,80 & 12,14 & 15,91 & 16,04 \\
\hline
\end{tabular}

$1 \_$Época 1 = milho com 10 folhas desenvolvidas; época 2 = milho no pendoamento.

2` Médias de tratamentos comparadas nas colunas, dentro do mesmo fator, seguidas por letras idênticas, não diferem significativamente pelo teste de Duncan, a $5 \%$ de probabilidade.

Tabela 4 - Efeitos de aplicações de herbicidas e de fontes e doses de nitrogênio em características de plantas de milho. EEA/ UFRGS, Eldorado do Sul-RS, 1999/00

\begin{tabular}{|c|c|c|c|c|}
\hline \multirow{2}{*}{ Fatores e tratamentos } & \multicolumn{2}{|c|}{ Massa seca da parte aérea (g) } & \multicolumn{2}{|c|}{ Teor de clorofila $\mathrm{a}^{\underline{3}}$} \\
\hline & Época $1^{1 /}$ & Época $2^{\frac{1}{\prime}}$ & Época 1 & Época 2 \\
\hline \multicolumn{5}{|l|}{ Fontes de nitrogênio } \\
\hline Uréia & $49,1 \mathrm{a}^{2 !}$ & $151,6 \mathrm{a}$ & $39,7 \mathrm{a}$ & $51,9 \mathrm{a}$ \\
\hline Nitrato de amônio & $48,8 \mathrm{a}$ & $148,8 \mathrm{a}$ & $40,5 \mathrm{a}$ & $52,4 \mathrm{a}$ \\
\hline \multicolumn{5}{|l|}{ Doses de N $\left(\mathrm{kg} \mathrm{ha}^{-1}\right)$} \\
\hline 0 & $49,2 \mathrm{a}$ & $149,0 \mathrm{a}$ & $37,5 \mathrm{~b}$ & $47,8 \mathrm{~b}$ \\
\hline 100 & $48,7 \mathrm{a}$ & $151,4 \mathrm{a}$ & $42,7 \mathrm{a}$ & $56,5 \mathrm{a}$ \\
\hline \multicolumn{5}{|l|}{ Herbicidas } \\
\hline Testemunha & 47,5 a & $147,1 \mathrm{a}$ & $40,3 \mathrm{ab}$ & $51,9 \mathrm{a}$ \\
\hline Glufosinate & $47,1 \mathrm{a}$ & $150,9 \mathrm{a}$ & $39,1 \mathrm{~b}$ & $51,9 \mathrm{a}$ \\
\hline Atrazine & $51,2 \mathrm{a}$ & $155,2 \mathrm{a}$ & $41,6 \mathrm{a}$ & $52,7 \mathrm{a}$ \\
\hline Glufosinate + atrazine & $49,9 \mathrm{a}$ & $147,5 \mathrm{a}$ & $39,4 \mathrm{~b}$ & $52,2 \mathrm{a}$ \\
\hline Médias & 48,9 & 150,2 & 40,1 & 52,2 \\
\hline $\mathrm{CV}(\%)$ & 13,74 & 12,59 & 7,09 & 5,17 \\
\hline
\end{tabular}

1/ Época 1 = milho com 10 folhas desenvolvidas; época 2 = milho no pendoamento.

${ }^{2} /$ Médias de tratamentos comparadas nas colunas, dentro do mesmo fator, seguidas por letras idênticas, não diferem significativamente pelo teste de Duncan, a 5\% de probabilidade.

3/ Leitura do clorofilômetro (leitura SPAD). 
Embora a toxicidade de $\mathrm{NH}_{4}^{+}$pareça representar o modo de ação primário de glufosinate, existem outros efeitos causados por este herbicida em plantas sensiveis (Ahrens, 1994), sendo um destes observado no conteúdo de clorofila, avaliado quando as plantas de milho apresentavam 10 folhas desenvolvidas (Tabela 4). Para esta variável, a utilização isolada de glufosinate reduziu o teor de clorofila em 3\% e, na aplicação seqüencial com atrazine, em $2 \%$, na primeira época. Mesmo considerando-se que essas reduções sejam relativamente baixas e o fato de não se encontrarem relatos na literatura sobre o efeito direto deste herbicida no teor de clorofila, Devine et al. (1993) salientam que a paralisação do ciclo de Calvin, ocasionada pelo glufosinate, resulta na canalização de alguma energia para a redução fotossintética de oxigênio molecular, $\mathrm{NO}_{2}{ }^{-}$, enxofre e fósforo. Em conseqüência, poderá ocorrer fotoinibição, resultando finalmente em peroxidação de lipídios da membrana via clorofila tripleto. Outro efeito pode estar associado à redução no teor de $\mathrm{N}$ na planta, como foi observado no florescimento do milho (Tabela 3), visto que deficiência de $\mathrm{N}$ diminui os níveis dos componentes fotossintéticos estruturais, como clorofila e ribulose bifosfato carboxilase (rubisco), com resultantes reduções na capacidade fotossintética e na eficiência da carboxilação (Lam et al., 1996).

Em ambos os anos de condução da pesquisa, a eficiência de uso do nitrogênio (EUN) não foi influenciada pelos tratamentos herbicidas e pelas fontes de $\mathrm{N}$ utilizadas (dados não apresentados). Na média dos fatores e tratamentos testados, os valores de EUN em 1997/98 foram de 49,2 e 42,4 g de MS/g de $\mathrm{N}$ aos $10 \mathrm{DAA}$ e aos 20 DAA, respectivamente. Em 1999/2000, os valores de EUN foram de 42,8 e 75,0 g de $\mathrm{MS} / \mathrm{g}$ de $\mathrm{N}$ para a primeira e segunda avaliações, respectivamente.

$\mathrm{Na}$ avaliação de rendimento de grãos, em ambos os anos, não foram observados efeitos dos herbicidas nem das fontes de nitrogênio (Tabelas 2 e 5). Embora no primeiro experimento tenha ocorrido aumento relativo de $8 \%$ no rendimento, quando foram utilizados $2.000 \mathrm{~g} \mathrm{ha}^{-1}$ de atrazine, este valor não foi significativo, provavelmente devido ao alto coeficiente de variação (27\%) observado. Em relação aos componentes do rendimento, no primeiro ano de condução do trabalho foi observado efeito dos herbicidas somente para peso de 1.000 grãos (Tabela 2), em que a utilização da dose cheia de atrazine aumentou em $8 \%$ o peso de grãos, em relação à testemunha não-tratada. No segundo ano, os tratamentos herbicidas influenciaram somente o componente número de espigas por planta (Tabela 5). Os resultados de rendimento e de componentes do rendimento demonstram que, mesmo ocorrendo efeitos dos herbicidas sobre o metabolismo de $\mathrm{N}$ na planta, estes são relativamente reduzidos para influenciar de forma significativa o rendimento da cultura. Em relação a isso, Hageman \& Lambert (1988) salientam que ganhos no rendimento de grãos são pouco prováveis de ocorrer se for usada somente uma característica enzimática relacionada ao metabolismo do N. Ressalta-se, novamente, o fato de que a multirregulação do metabolismo do $\mathrm{N}$ torna complexa a identificação de pontos metabólicos específicos que sejam mais limitantes para o incremento do rendimento (Bredemeier \& Mundstock, 2000).

Ao se compararem conjuntamente os resultados obtidos nos dois experimentos, constatase que aplicação de $\mathrm{N}$ em cobertura na cultura do milho promove aumento na maioria dos componentes do rendimento e incrementa em $35 \%$ o rendimento de grãos e que esse efeito do $\mathrm{N}$ ocorre de forma independente das fontes de $\mathrm{N}$ utilizadas (uréia e nitrato de amônio). Em geral, não ocorre interação entre os fatores relacionados à utilização dos herbicidas inibidores do fotossistema II (atrazine) e da sintese de glutamina (glufosinate) e à aplicação de $\mathrm{N}$ em cobertura no milho. O uso destes herbicidas em subdoses, aplicadas isoladamente ou combinadas, não afeta de modo relevante o rendimento de grãos de milho nem os componentes do rendimento. O herbicida atrazine mostra pouca consistência em afetar os teores de clorofila e de $\mathrm{N}$ em milho, mas, em algumas situações, sua ação é favorável, especialmente quando usado em dose cheia ou isoladamente. O herbicida glufosinate, usado em subdoses, em geral não afeta o teor de $\mathrm{N}$ em milho, porém, em alguns casos, afeta o de clorofila e, na dose de $80 \mathrm{~g} \mathrm{ha}^{-1}$, promove aumento do teor de $\mathrm{N}$. 
Tabela 5 - Efeitos de aplicações de herbicidas e de fontes e doses de nitrogênio em características de plantas e grãos de milho. EEA/UFRGS, Eldorado do Sul-RS, 1999/00

\begin{tabular}{|c|c|c|c|c|}
\hline \multirow{2}{*}{$\begin{array}{l}\text { Fatores e } \\
\text { tratamentos }\end{array}$} & \multicolumn{4}{|c|}{ Características de plantas e grãos de milho } \\
\hline & $\begin{array}{l}\text { Espigas por planta } \\
\qquad\left(\mathrm{n}^{\underline{\mathrm{o}}}\right)\end{array}$ & $\begin{array}{c}\text { Grãos por espiga } \\
\left(\mathrm{n}^{\mathrm{o}}\right)\end{array}$ & $\begin{array}{c}\text { Peso de } 1.000 \text { grãos } \\
(\mathrm{g})\end{array}$ & $\begin{array}{l}\text { Rendimento de } \\
\text { grãos }\left(\mathrm{kg} \mathrm{ha}^{-1}\right)\end{array}$ \\
\hline \multicolumn{5}{|l|}{ Fontes de nitrogênio } \\
\hline Uréia & $0,97 \mathrm{a}^{\underline{1} /}$ & $440 \mathrm{a}$ & $281 \mathrm{a}$ & $6.671 \mathrm{a}$ \\
\hline Nitrato de amônio & $0,97 \mathrm{a}$ & $447 \mathrm{a}$ & $279 \mathrm{a}$ & $6.871 \mathrm{a}$ \\
\hline \multicolumn{5}{|l|}{ Doses de N $\left(\mathrm{kg} \mathrm{ha}^{-1}\right)$} \\
\hline 0 & $0,97 \mathrm{a}$ & $393 b$ & $272 b$ & $5.770 \mathrm{~b}$ \\
\hline 100 & $0,97 \mathrm{a}$ & $494 \mathrm{a}$ & $288 \mathrm{a}$ & $7.772 \mathrm{a}$ \\
\hline \multicolumn{5}{|l|}{ Herbicidas } \\
\hline Testemunha & $0,96 \mathrm{~b}$ & $442 \mathrm{a}$ & $281 \mathrm{a}$ & $6.747 \mathrm{a}$ \\
\hline Glufosinate & $0,95 \mathrm{~b}$ & $445 \mathrm{a}$ & $280 \mathrm{a}$ & $6.795 \mathrm{a}$ \\
\hline Atrazine & $0,97 \mathrm{ab}$ & $460 \mathrm{a}$ & $278 \mathrm{a}$ & $6.878 \mathrm{a}$ \\
\hline Glufosinate + atrazine & 0,99 a & $425 \mathrm{a}$ & $280 \mathrm{a}$ & $6.665 \mathrm{a}$ \\
\hline Médias & 0,97 & 443 & 280 & 6.771 \\
\hline $\mathrm{CV}(\%)$ & 4,94 & 13,77 & 5,18 & 16,42 \\
\hline
\end{tabular}

${ }^{1}$ Médias de tratamentos comparadas nas colunas, dentro do mesmo fator, seguidas por letras idênticas, não diferem significativamente pelo teste de Duncan, a 5\% de probabilidade.

\section{LITERATURA CITADA}

AHRENS, W.H., Herbicide handbook. 7.ed. Champaign: WSSA, 1994. 352p.

ASHTON, F.M.; CRAFTS, A.S. Mode of action of herbicides. New York:Wiley-Interscience, 1973. 504 p.

BREDEMEIER, C.; MUNDSTOCK, C.M. Regulação da absorção e assimilação do nitrogênio nas plantas. R. C. Rural, v.30, n.2, p.365-372, 2000.

CHURCHILL, K.; KLEPPER, L. Effects of ametryn [2 - (ethylamino) - 4-(is opropylamino) - 6(methylthio)-s-triazine] on nitrate reductase activity and nitrite content of wheat (Triticum aestivum L.). Pest. Biochemi. Physiol., v. 12, n.2, p.156-162, 1979.

DEVINE, M.; DUKE, S.O.; FEDTKE, C. Physiology of herbicide action. Englewood Cliffs: PTR Prentice Hall, 1993. 441p.

DUKE, S.O. Effects of herbicides on nonphotosynthetic biosynthetic processes. In: DUKE, S.O., ed. Weed physiology: herbicide physiology. Boca Raton: CRC Press, 1985. p.91-112.
EMPRESA BRASILEIRA DE PESQUISA AGROPECUÁRIA - EMBRAPA. Centro Nacional de Pesquisa de Solos. Sistema brasileiro de classificação de solos. Brasília: 1999. 412p.

FEDTKE, C. Formation of nitrite in plants treated with herbicides that inhibit photosynthesis. Pest. Sci., v.8, n.2, p.152-156, 1977.

HAGEMAN, R.H.; LAMBERT, R.J. The use of physiological traits for corn improvement. In: SPRAGUE, G.F.; DUDLEY, J.W. Corn and corn improvement. 3.ed. Madison: ASA/CSSA, 1988. p.431-461.

HESS, F.D. Mode of action of glufosinate. In: PURDUE UNIVERSITY. Herbicide action. West Lafayette: 1995. p.143-148.

HUPPE, H.C.; TURPIN, D.H. Integration of carbon and nitrogen metabolism in plant and algal cells. Ann. Rev. Plant Physiol. Plant Molec. Biol., v.45, p.577-607, 1994.

KLECZKOWSKI, L.A. Inhibitors of photosynthetic enzymes/carriers and metabolism. Ann. Rev. Plant Physiol. Plant Molec. Biol., v.45, p.339367, 1993. 
KLEPPER, L.A. Effects of certain herbicides and their combinations on nitrate and nitrite reduction. Plant Physiol., v.64, n.2, p.273-275, 1979.

KLEPPER, L.A. Inhibition of nitrite reduction by photosynthetic inhibitors. Weed Sci., v.23, n.3, p.188-190, 1975.

KLEPPER, L.A. Nitrite accumulation within herbicide-treated leaves. Weed Sci., v.24, n.6, p.533-535, 1976.

LAM, H.M.; COSCHIGANO, K.T.; OLIVEIRA, I.C.; MELO-OLIVEIRA, R.; CORUZZI, G.M. The molecular-genetics of assimilation into amino acids in higher plants. Ann. Rev. Plant Physiol. Plant Molec. Biol., v.47, p.569-93, 1996.

LAM, H.M.; COSCHIGANO, K.T.; SCHULTZ, C.; MELO-OLIVEIRA, R. TJADEN, G.; OLIVEIRA, I.; NGAI, N.; HSIEH, M.; CORUZZI, G.M. Use of Arabidopsis mutants and genes to study amide amino acid biosynthesis. Plant Cell, v.7, n.7, p.887-898, 1995.
LEA, J.L. Nitrogen metabolism. In: LEA, J.L.; LEEGOOD, R.C. Plant biochemistry and molecular biology. Chichester: Wiley, 1993. p. 155-180.

MOHANADAS, S.; WALLACE, W.; NICHOLAS, D.J.D. Effects of atrazine on the assimilation of inorganic nitrogen in cereals. Phytochemistry, v.17, n.6, p.1021-1028, 1978.

SINGH, P.; PRAKASH, S.; GROVER, H.L. Effect of 2,4-D on the nitrate assimilation process in cowpea shoot. Pest. Biochem. Physiol., v.61, n.1, p.15-20, 1998.

TEDESCO, M.J.; VOLKSWEISS, S.J.; BONHEN, H. Análise de solo, plantas e outros materiais. Porto Alegre: Universidade Federal do Rio Grande do Sul, 1985. 188p. (Boletim Técnico, 5).

VON WIRÉN, N.; GAZZARRINI, S.; GOJON, A.; FROMMER, W.B. The molecular physiology uptake and retrieval. Current Opin. Plant Biol., v.3, n.3, p.254-261, 2000. 